\title{
Prognostic Factors of Pediatric Emergency Anesthesia at the University Hospital of Cocody
}

\author{
N'Guessan YF*, Abhe CM, Ouattara A, Coulibaly KT, Ogondon B, Mobio MP, Netro D, Assah NL, Binlin DR, Pete \\ YD, Eyengue $\mathbf{O}$ and Brouh Y \\ Department of Anesthesia, Université Félix Houphouët-Boigny, Côte d'Ivoire
}

Submission: December 19, 2016; Published: March 31, 2017

*Corresponding author: Yapi Francis N'Guessan, Department of Anesthesia RÃ (C) animation at the UFR of medical sciences department of rescue at the CHU de Cocody, BPV 13 Abidjan, Côte d'Ivoire, Tel: +00225-05601060; Email: yapifrancis@yahoo.fr

Summary

FIn sub-Saharan Africa and singularly in Ivory Coast the anesthesia of the children in urgen cyisa real Challenge because of many risks to which it exposes. The lack of data at the University Hospital of Cocody has motivated this study whose the aim was to search the elements which can make it possible to predict the pediatric mortality in case of anesthesia in urgency in order to anticipate their occurred and in the worst case drawing up a protocol medical car for the children.

Population and method: It was carried out over one 05 years period going from July 2008 to June 2012. It concerned all the children whose age lay between 0 and 15 years, which were taken charges with the min urgency under anesthesia with the service with anesthesia reanimation D "a Hospital and University D "Abidjan-Coast D" Ivory.

Results and discussion: The factors forecast raised in this study are: Digestive pathologies, the young age, classification ASA, the absence of doctor anesthetist to the block, interventions carried out the night.

Conclusion: The good practice of the pediatric anesthesia in urgency would pass by staff training in anesthesia of the children with blocks dedicated and equipped.

Keywords: Anesthesia; Pediatric; In urgency; Mortality; Prevention

\section{Introduction}

The basic principles of the anesthesia have always been the same ones any where in the world. But their application would require all the more important adaptations because of two main constraints: the subject is young and disabilities are many [1].

This assertion is confirmed by most studies which report that mortality and morbidity are strongly influenced by the age. In developed countries, according to the register of perioperative mortality, the incidence of the cardiac arrests due to the anesthesia is: $1.4+0.45$ per 10000 anesthesia, $55 \%$ concerned infant of less than one year. The anesthesia in urgency accounted for $21 \%[2,3]$.

In Ivory Coast, a study carried out [4] in 1996 on the intra operative cardiac arrest sand in the recovery phase in a university hospital of reference, found an incidence of 01 per 250 anesthesia or $0.4 \%$. Unfortunately, the children accounted for $67 \%$ of the cardiac arrests. 3103 anesthesia were recorded. Generally practiced in emergency, the pediatric anesthesia could concern children in precarious situation, either because of an extreme immaturity of the major functions (high prematurity), or because of severe pathology acquired or constitutional of ten genetically transmitted which can engage the vital prognosis in the absence of an adequate support through gestures of reanimations [3].

In sub-Saharan Africa and taking into account our conditions of exercise, the practice of the anesthesia of the children in case of urgency is a real challenge because of many risks to which it exposes [5]. The absence of data in the highest reference hospital has motivated this survey whose objective was to search the elements which can make it possible to predict the pediatric mortality anesthesia in urgency in order to anticipate their occurrence and in the worst case drawing up a protocol of specific medical care for children.

\section{Equipment and Method}

It was about are prospective, descriptive and analytical study conducted in the department of anesthesia and intensive care of the largest hospital of reference in Ivory Coast over one 05 years 
period. All the children whose age was between 0 and 15 years and who had a surgical operation in emergency were included. An index card collection was the essential material support of our study. This card included the following elements: Epidemiologic parameters, The pre-anesthetic evaluation, anesthetic histories, classification ASA, the anesthetic data (the type of anesthesia, the type of premedication, the type of induction, the control of the air routes), the kind of pathologies supported; the quality of the expert having realized anesthetic induction, Anesthetic accidents and incidents.

\section{Anesthetic accidents}

Any major complication occurring during surgery with consequences on the condition of the patient.

\section{Incidents}

Any minor complication occurring during surgery and which is without consequence on the clinical state of the patient and the post-anesthetic evolution of the children.

All these data have been recorded and processed with the Software EPI Info version 6.04. The qualitative variables are expressed in the forms of proportions and the quantitative variables are expressed on average with their standard deviation. The graphs were carried out starting from the software Microsoft Office Excel 2007. The statistical test used for the comparison of the qualitative variables was Khi2. The test was significant if $\mathrm{p}<0.05$. The results will be expressed in tables.

\section{Results}

\section{General characteristics (Figure 1)}

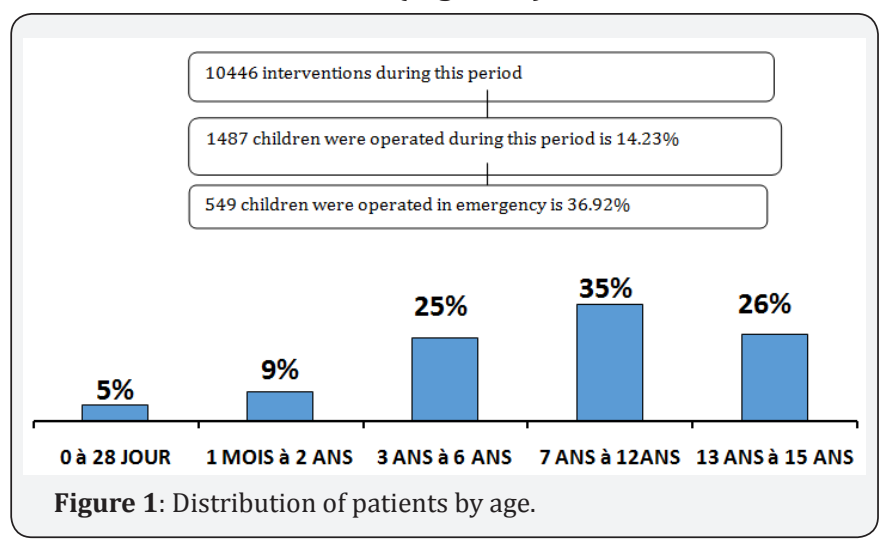

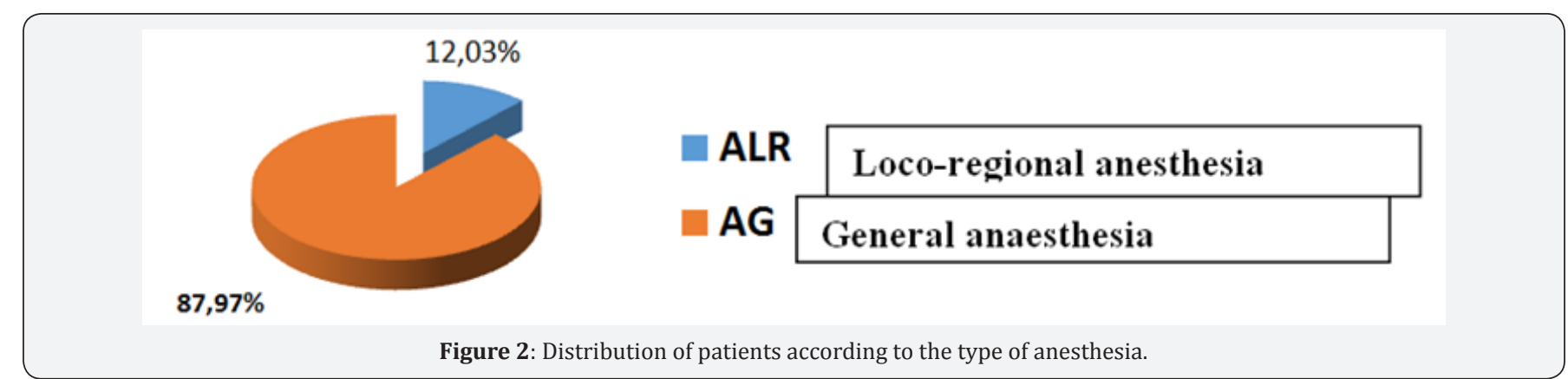

Neonatal anesthesia account for $5 \%$ of the work force.The most represented age group is [07-12 years]. The mean age was $08.66 \pm 5.41$ with a range of $0-15$ years. $100 \%$ of the children were seen in consultation. The predominant ASA (American society of anesthesiology) I and II class with $78 \%$ of the work force (Figure 2).

General anesthesia was the most practiced in $87.97 \%$ of cases. $71.22 \%$ of inductions were performed intravenously. Intubation of the trachea was performed in $73.09 \%$ of patients. $71.22 \%$ of children had intravenous induction $63.75 \%$ of inductions performed in the absence of a resuscitation anesthesiologist (Table 1-5).

Table1: The distribution of patients according to surgical specialty. Traumatology and digestive surgery accounted for nearly $71 \%$ of interventions.

\begin{tabular}{|c|c|c|}
\hline Type of Surgery & Effective & Percentage \% \\
\hline Traumatology & 212 & 38,6 \\
\hline Digestive Surgery & 178 & 32,4 \\
\hline ORL Surgery & 38 & 06,98 \\
\hline Stomatology & 28 & 05,10 \\
\hline
\end{tabular}

\begin{tabular}{|c|c|c|}
\hline $\begin{array}{c}\text { Gynecology and } \\
\text { obstetrics }\end{array}$ & 77 & 14,00 \\
\hline Urologicalsurgery & 16 & 02,91 \\
\hline Total & $\mathbf{5 4 9}$ & $\mathbf{1 0 0 , 0 0}$ \\
\hline
\end{tabular}

Table 2: The distribution of patients according to gynecological and obstetric pathologies.

\begin{tabular}{|c|c|c|}
\hline $\begin{array}{c}\text { Gynecological and Obstetric } \\
\text { Pathologies }\end{array}$ & Workforce & $\begin{array}{c}\text { Percentage } \\
\text { (\%) }\end{array}$ \\
\hline Caesarean section (immature pelvis) & 52 & 67,5 \\
\hline Eclampsia (acute fetal distress) & 10 & 12,98 \\
\hline Perineal trauma & 5 & 06,53 \\
\hline Retro-placental hematoma & 4 & 05,19 \\
\hline Ectopic pregnancy & 3 & 03,90 \\
\hline Postpartum Hemorrhage & 3 & 03,90 \\
\hline Total & $\mathbf{7 7}$ & $\mathbf{1 0 0 , 0 0}$ \\
\hline
\end{tabular}


Table 3: The distribution of patients according to the evolution. $20 \%$ of patients had complications after surgery.

\begin{tabular}{|c|c|c|}
\hline Evolution & Effective & Percentage (\%) \\
\hline Pediatric Surgery transfer & 439 & 80,00 \\
\hline intensive care unit transfer & 105 & 19,12 \\
\hline $\begin{array}{c}\text { Died (Operating Room and Post- } \\
\text { interventional care room.) }\end{array}$ & 5 & 0,88 \\
\hline Total & $\mathbf{5 4 9}$ & $\mathbf{1 0 , 0 0 0}$ \\
\hline
\end{tabular}

Table 4: The distribution of patients according to Accidents and Incidents. $77 \%$ des incidents sont respiratoire.

\begin{tabular}{|c|c|c|c|}
\hline Risk factors & Incident & $\begin{array}{c}\text { No } \\
\text { Incident }\end{array}$ & $\begin{array}{c}\text { CHI 2 and P } \\
\text { value }\end{array}$ \\
\hline Age: $<30$ months \\
$>30$ months & 24 & 50 & 34,62 \\
\cline { 2 - 4 } & 7 & 466 & {$[\mathrm{P}=0,000000]$} \\
\hline $\begin{array}{c}\text { Digestive Surgery } \\
\text { Other surgery }\end{array}$ & 15 & 163 & 2,3 \\
\cline { 2 - 4 } & 16 & 353 & {$[\mathrm{P}=0,021]$} \\
\hline Time Frame: Short time $<2 \mathrm{H}$ & 14 & 244 & 0,92 \\
\cline { 2 - 4 } long time $>2 \mathrm{H}$ & 17 & 274 & {$[\mathrm{P}=0,061]$} \\
\hline Anesthetist: Present & 23 & 327 & 2,56 \\
\cline { 2 - 4 } Missing & 8 & 291 & {$[\mathrm{P}=0,0356]$} \\
\hline
\end{tabular}

Table 5: Risk factors repartition.

\begin{tabular}{|c|c|c|c|}
\hline Anesthesia Technique: AG & 29 & 454 & 2,04 \\
\cline { 2 - 4 } ALR & 2 & 64 & {$[\mathrm{P}=0,046]$} \\
\hline ASA classification: ASA I et II & 7 & 421 & 0,07 \\
\cline { 2 - 4 } ASA > II & 24 & 95 & {$[\mathrm{P}=0,0217]$} \\
\hline Time of the intervention: Days & 14 & 324 & 0,49 \\
\cline { 2 - 4 } Night & 17 & 194 & {$[\mathrm{P}=0,052]$} \\
\hline
\end{tabular}

\section{Comments}

The low number of neonatal anesthesia is explained by the high number of deaths before transfer to a specialized structure. These structures were insufficient number with a non-existent evacuation system. This management of fewer frequent surgical children decreases the experience of the personnel of these specialized structures with equipment increasingly defective. The majority of Anesthesia Consultations were performed by anesthetists in $90 \%$ of cases. General anesthesia was performed in $88 \%$ of children. $71.22 \%$ of the inductions were performed intravenously. During induction, propofol was the most used with $41.6 \%$. For muscle relaxation, vecuronium (Norcuron $®$ ) was the most used curare in the operating room in $99.4 \%$. Fentanyl is frequently used as an analgesic in the operating room in about $91 \%$. $63.75 \%$ of inductions were performed in the absence of a resuscitation anesthesiologist. Post-surgical care was provided by Surgeons in $80 \%$ because our intensive care units are adults with one or two places for children. As regards loco-regional anesthesia used in $12 \%$ of children, it was essentially spinal anesthesia in 95\% mainly in obstetrics and $4 \%$ caudal and around 1\% peripheral block. $20 \%$ of patients had complications after surgery. These complications were mainly respiratory $(77 \%)$ with the incidence of cardiac arrest which was 128 per 10000 anesthesia. Most studies made on the incidents and accidents in pediatric anesthesia in sub-Saharan Africa had similar or higher results.

So in Benin, Zoumenou et al. [6] general anesthesia was used in $94 \%$ of children. Regional anesthesia was used in 1.7\% of children at CNHU and $17 \%$ of children at Hôpital de la Mèreet de l'Enfant Lagune. Inhalational induction was the commonest technique used. Halothane was the only inhalational agent available for induction. Seventy-two percent of children having general anesthesia were intubated. Muscle relaxation was used in $48 \%$ of cases, only with pancuronium. The available perioperative monitoring equipment was not used regularly. All children having general anesthesia breathed spontaneously with manual assistance. There were eight cardiac arrests recorded, giving an incidence of 156 cardiac arrests per 10,000 anesthetics. Hypoxia was the commonest cause of cardiac arrest. The mortality associated with cardiac arrest was very high (62\%). There were three prognostic factors that predicted a poor outcome: age $<1$ year, emergency surgery and an ASA score of three or more.

In congo, Otiobanda et al. [7] brought back a cardiac arrest perioperative for a sample of 180 children operated to the university hospital of Brazzaville (either 55 out of 10,000 anaesthesia) and a perioperative mortality estimated at 270 out of 10,000 anesthesia's. In burkina faso, Kaboré et al. [8] reported a perioperative mortality rate of 624 out of 10,000 anesthesias in the service at the pediatric university hospital of Ouagadougou. In gabon, Essol Aandal et al. [9] brought back a lower morbidity, estimated at 11 out of 10,000 anesthesias.

Methodologies of the sevarious studies are not always comparable; in the same way, the partial or total responsibility of the anesthesia was not explicitly studied there. Our values were higher than that reported from Maghreb which was from 2.23 out of 10,000 anesthesias [10].

In the POCA Registry of 1994, 63 institutions enrolled and submitted 289 cases of cardiac arrest. Of these, 150 arrests were judged to be related to anesthesia. Cardiac arrest related to anesthesia had an incidence of $1.4 \pm 0.45$ (mean \pm SD) per 10,000 instances of anesthesia and a mortality rate of $26 \%$. Medication-related (37\%) and cardiovascular (32\%) causes of cardiac arrest were most common, together accounting for $69 \%$ of all arrests. Cardiovascular depression from halothane, alone or in combination with other drugs, was responsible for two thirds of all medication-related arrests. Thirty-three percent of the patients were American Society of Anesthesiologists physical status 1-2; in this group, $64 \%$ of arrests were medication-related, compared with $23 \%$ in American Society of Anesthesiologists physical status $3-5$ patients $(\mathrm{P}<0.01)$. Infants younger than 1 year of age accounted for $55 \%$ of all anesthesia-related arrests. Multivariate analysis demonstrated two predictors of mortality: American Society of Anesthesiologists physical status 3-5 (odds 
ratio, 12.99; 95\% confidence interval, 2.9-57.7), and emergency status (odds ratio, 3.88; 95\% confidence interval, 1.6-9.6).

Digestive pathologies were found to be a prognostic factor. The reasons given in our exercise conditions were: immature organs, high sensitivity of children to hypovolemia, difficulties with parenteral nutrition, anesthetic risks with halothane, and per-and post-operative hypothermia [6]. Western studies found that $61.1 \%$ of anesthetized children for visceral surgery were treated with $\mathrm{CHG}$ or $\mathrm{CHU}$. They recommend an organization of the management of pediatric anesthesia with protocols, reference hospitals, specialized anesthesia of the remedies. In sub-Saharan Africa, early diagnosis and pre-anesthesia assessment, accessible and easy-to-use child-specific materials and medications [6].

All the publications which described the practice of the pediatric anesthesia bring back a morbidity and excessively high and unacceptable perioperative mortality in comparison with reference levels in the developed countries [11]. We however realized in all these studies to show that the risk was all the more high as the child is young, new-born child and the infants have more raised rates of mortality [2,3]. These incidents with the disastrous consequences could complicate the fate of subSaharan Africa which bases its hope son youth [4]. The doctor's anesthetist absence in the operating room was also found like one of the independent factors forecasts in this study. In Africa and every where in the world as shows in most studies, the absent or an in experienced anesthetist was revealed like factor major forecast [1,3,11-13].

For these authors, When we take care of children, it are necessary to satisfy certain specific conditions as a preliminary, corresponding to the age group concerned, as well as regards staff as of structures. In general-purpose hospitals it would be necessary to have a space dedicated to the child and encourages the creation of pediatric references hospital. Each work place where anesthetists will take care of children should be equipped with pediatric equipment $[4,2,14]$ in spite of we did not find a direct link statistical, this study pointed out a more significant number of deaths under general anesthesia compared to loco regional anesthesia, in the surgeries practiced in the night on children who were ASA class III and IV and which was operated after a long period of waiting.

The significant number of incident during the general anesthesia could explained by the fact that it was the technique more practiced in pediatry during this time. About $80 \%$ of the ventilation support incidents in this study could probably be related to the general anesthesia. A significant number of authors face respiratory complications in pediatric anesthesia. According to them, the problems of air routes would be the most frequent cause of pediatric anesthesia complications $[11,15]$.

Thus, they recommended the use of probe of intubation with good-sized balloon with monitoring of the pressure $[16,17]$.
Keenan RL [18] in his studies on the factors forecasts of the brady cardiain pediatric anesthesia had found: classification ASA, urgency, the time of interventions higher than 4 hours and thein experienced supervisory anesthetist [18]. But according to Draper and collar $[19,20]$, the risks related to the loco regional anesthesia are not negligible when it is combined with the general anesthesia.

\section{Conclusion}

The children are not adults in miniature. The incidents in pediatric anesthesia differ to a significant degree compared to the incidents concerning the adults. These risks are all the more high as the child is young and the surgery is urgent. The good practice of the pediatric anesthesia in urgency would pass by a staff training in anesthesia of the children with blocks dedicated and equipped, by an initial training and the maintenance of knowledge of staff. A great hope is also place don't he use of the new agents and technical anesthetic.

\section{References}

1. .Leprêtre O, Paut 0 (2005) Anesthésie du nouveau -né. Conférences d'actualisation SFAR pp. 354-378.

2. Orliaguet $\mathrm{G}$, Nathalie B (2008) Nausée et Vomissement post opératoire chez l'enfant. Mapar Paris, France, pp. 519-529.

3. Françis Veckmans (2012) Patient à estomac plein. In : Dalens B, Veckmans $F$ (Eds.), Anesthésie su terrain pédiatriques à risque. Swauramps Medical, Paris, France, p. 5-12.

4. BrouhY, Amonkou A, Yeo T, Soro L, Kouame E, et al. (1996) Les arrêts cardiaques peropératoires et dans la phase de réveil au CHU de Yopougon à propos de 3103 anesthésies. Urgences Médicale 15: 255259.

5. Ombredanne L (1946) Anesthésie pédiatrique-chirurgie infantile In : Précis clinique et opératoire de chirurgie infantile,5ièmeed, Masson et Cie éditeur, paris, France, pp. 1053.

6. Zoumenou E, Gbénou S, Assouto P, OuroBang'na Maman AF, Lokossou T, et al. (2010) Pediatric anesthesia in developing countries: experience in the two main university hospitals of Benin in West Africa. Pediatr Anaesth 20(8): 741-747.

7. Otiobanda GF, Mahoungo-Guimbi KC, Odzebe AWS, Mboutol Mandavo C, Ekouya Bowassa G, et al. (2011) Pratique de l'anesthésie pédiatrique au centre hospitalier et universitaire de Brazzaville. Rev Afr Anesth Med Urg 16(1).

8. Kaboré RAF, Bandre EF, Sankara L, Sanou A, Ouédraogo N, et al. (2009) Étude de la mortalité dans un service de chirurgie pédia-trique africain au sud du Sahara. Med Afr N 56: 729-732.

9. Essola L, Sima Zué A, Obame R, Ngomas JF, Kamel G, et al. (2013) Anesthésie pédiatrique en milieu africain : expérience d'un hôpital gabonais à vocation adulte. Rev Afr Anesth Med Urg 18(1).

10. Hmamouchi B, Neijmi S, Benkhalifa S, Dehdouh A, Chlilek A (2009) Morbimortalité en anesthésie pédiatrique au Maghreb. Ann Fr Anesth Reanim 28(7): 671-673.

11. Morray JP, Geiduschek JM, Ramamoorthy C, Haberkern CM, Hackel A, et al. (2000) Anesthesia related cardiac arrest in children. Initial findings of the pediatric perioperative cardiac arrest (POCA) registry. Anesthesiology 93(1): 6-14.

12. Auroy Y, Ecoffey C, Messiah A, Rouvier B (1997) Relationship between complications of pediatric anesthesia and volume of pediatric anesthetics. Anesth Analg 84(1): 234-235. 
13. Murat I, Constant I, Maud'huy H (2004) Perioperative anaesthetic morbidity in children: a database of 24,165 anaesthetics over a 30-month period. Paediatr Anaesth 14(2): 158-166.

14. Frei F, Dangel P, Gemperle G, Hasse E, Jöhr M, et al. (1993) In welchen Spitälern sollen Säuglinge und Kleinkinder operiert werden? Schweiz Aerztezeitung 74: 140-142.

15. Weiss M, Schmidt J, Eich C, Stelzner J, Trieschmann U, et al. (2011) Hand lungsempfeh lung zur Prävention und Behandlung des unerwartet schwierigen Atemwegs in der Kinde ranästhesie. Anästh Intensivmed Supple 3: 53-64.

16. Weiss M, Dullenkopf A, Fischer JE, Keller C, Gerber AC (2009) Prospective randomized controlled multi-centre trial of cuffed or uncuffed endotracheal tubes in small children. Br J Anaesth 103(6): 867-873.

This work is licensed under Creative Commons Attribution 4.0 License

DOI: $10.19080 / J A I C M .2017 .02 .555579$
17. Salgo B, Schmitz A, Henze G, Stutz K, Dullenkopf A, et al. (2006) Evaluation of a new recommendation for improved cuffed tracheal tube size selection in infants and small children. Acta Anaesthesiol Scand 50(5): 557-561.

18. Keenan RL, Shapiro JH, FR Kane, PM Simpson (1994) Bradycardia during anesthesia in infants. An epidemiologic study. Anesthesiology 80(5): 976-982.

19. Mercier C, Laffon M (2001) Risques et bénéfices de l’anesthésie chez l'enfant In : Conférences d'actualisation $40^{\text {ième }}$ congrès national SFAR pp. 225-244.

20. Orliaguet G, Salvi N Aspects juridiques de l'anesthésie pédiatrique hors centre de référence.

\section{Your next submission with Juniper Publishers} will reach you the below assets

- Quality Editorial service

- Swift Peer Review

- Reprints availability

- E-prints Service

- Manuscript Podcast for convenient understanding

- Global attainment for your research

- Manuscript accessibility in different formats ( Pdf, E-pub, Full Text, Audio)

- Unceasing customer service

Track the below URL for one-step submission https://juniperpublishers.com/online-submission.php 